\title{
Determinants of Modern Contraceptive Use among Women of Reproductive Age in Tanzania: Evidence from Tanzania Demographic and Health Survey Data
}

\author{
Paulo Lino Kidayi', Sia Msuya', Jim Todd ${ }^{2}$, Chuki Christina Mtuya ${ }^{3}$, Tara Mtuy², \\ Michael Johnson Mahande ${ }^{*}$ \\ ${ }^{1}$ Institute of Public Health, Department of Epidemiology and Biostatistics, Kilimanjaro Christian Medical \\ University College, Moshi, Tanzania \\ ${ }^{2}$ London School of Hygiene \& Tropical Medicine, London, UK \\ ${ }^{3}$ Fuculty of Nursing, Kilimanjaro Christian Medical University College, Moshi, Tanzania \\ Email: Paulo.kidayi@gmail.com, siamsuya@hotmail.com, jmmahande@gmail.com, Jim.Todd@lshtm.ac.uk, \\ cmtuya @yahoo.co.uk, Tara.Mtuy@Ishtm.ac.uk
}

Received 24 March 2015; accepted 26 June 2015; published 29 June 2015

Copyright (C) 2015 by authors and Scientific Research Publishing Inc.

This work is licensed under the Creative Commons Attribution International License (CC BY). http://creativecommons.org/licenses/by/4.0/

(c) ()

\section{Abstract}

Introduction: Tanzania is among of the African countries with high maternal and child mortality rates and fast growing population. It also has high fertility rate and a huge unmet need for family planning. Contraceptive use reported to avert more than 1 million maternal deaths in Sub-Saharan Africa due to decline in fertility rate and thus help to achieve MDG 4 and 5. Therefore, this study aimed to determine factors influencing modern contraceptive use among women aged 15 - 49 years in Tanzania. Methods: This was a secondary analysis of Tanzania Demographic Health Survey (TDHS), 2010. A total of 475 clusters (urban and rural) composed of 9663 households were selected. During the survey, a total of 10,139 women aged 15 - 49 years were interviewed about sexual and reproductive matters using a standardized questionnaire. We restricted our analysis to married/cohabiting women $(n=6412)$ responded for in individual records and domestic violence $(n=4471)$. Univariate and multiple logistic regression analyses were performed using Stata version 11.0. Odds ratios with $\mathbf{9 5 \%}$ confidence intervals for determinants of modern contraceptive use were estimated. A P value of $5 \%(2$ tails) was considered statistically significant. Results: Women empowerment (OR $=1.4 ; 95 \% \mathrm{CI}: 1.13-1.63)$, male-female age difference of less or equal to nine (OR = 1.6; $95 \mathrm{CI}$ : 1.01 - 2.66), and advice given at health care facilities on family planning (OR = 1.6; $95 \mathrm{CI}$ : 1.37 - 1.96) were predictors of modern contraceptive use. Woman sexual violence

${ }^{*}$ Corresponding author.

How to cite this paper: Kidayi, P.L., Msuya, S., Todd, J., Mtuya, C.C., Mtuy, T. and Mahande, M.J. (2015) Determinants of Modern Contraceptive Use among Women of Reproductive Age in Tanzania: Evidence from Tanzania Demographic and Health Survey Data. Advances in Sexual Medicine, 5, 43-52. http://dx.doi.org/10.4236/asm.2015.53006 
was not associated with modern contraceptive use. Conclusions: The predictors of modern contraceptive use in our study correspond with previous studies in low and middle income countries. Women empowerment, male-female age difference, and child desire were important predictors for modern contraceptive use. This highlights the need to promote contraceptive use among women of reproductive age.

\section{Keywords}

\section{Determinants, Modern Contraceptive Use, Intimate Partner Violence, Tanzania}

\section{Introduction}

Family planning (FP) is among the indicators of the Millennium Development Goals (MDG). FP prevents unwanted pregnancies and eliminates recourse to abortions. Both short and long inter-pregnancy interval (IPI) is associated with adverse pregnancy outcomes such as preterm birth, low birth weight, small for gestation age and perinatal death [1]. To prevent these adverse pregnancy outcomes, birth spacing has been considered as an effective intervention. A recent commentary on Family Planning in the Lancet, accurately summarised the impact of meeting the contraceptive needs as "According to Singh and colleagues [2], meeting the contraceptive needs of 215 million women with a unmet need for modern contraception would reduce unintended pregnancies by more than two thirds, avert $70 \%$ of maternal deaths, $44 \%$ of newborn deaths, and $73 \%$ of unsafe abortions, and reduce by $76 \%$ the number of women needing medical care for complications related to unsafe abortion. In addition to these health benefits, the resulting reduction in fertility and population growth would bring substantial socioeconomic and environmental benefits” [3]. FP enables couples or family/women to plan when to have children and use birth control to delay (spacing) or number of children.

Unmet need for family planning decreased worldwide from $15.4 \%$ in 1990 to $12.3 \%$ in 2010 [4]. Tanzania is among the countries that have made slow progress towards achieving MDG 4 and 5. It has a high unmet need for contraceptives $25 \%$ and has high total fertility rate 5.4, high maternal mortality rate (446 per 100,000) and high neonatal mortality rate (25 per 1000) compared with the target of 5\%, 4.7, 193 per 100,000, and 19 per 1000 by 2015 [5].

Previous analysis of TDHS showed an association between family planning use and socio-demographic characteristics. However, there is limited information about effects of partner characteristics (male-female age difference, education, and male controlling behavior), women empowerment, decision making on family planning, partner desire for childbearing and intimate partner violence, on contraceptive use. Addressing these identified factors may help to improve access and use of modern contraceptives, resulting in reduction of neonatal and maternal mortality rate.

According to TDHS 2010 report, knowledge, attitudes, practice, beliefs and socio-demographic factors were associated with modern contraceptive use among women of reproductive group. Literature also has showed that women empowerment, partner characteristics, partner violence, wife beating, and child preference are associated with modern contraceptive use among married women in low income countries [6]-[9]. But, the TDHS 2010 did not address these important factors. The few studies that have investigated have reported contradictory findings such as association of intimate partner violence and contraceptive. Some results were positive and others negative and had used relative small samples. This study investigated two major gaps (questions) that were not addressed in the 2010 TDHS report, 1) What are the factors that promote use of modern contraceptive use among women of reproductive age in Tanzania? 2) What are the barriers for use of modern contraception in this group? Therefore, we aimed to investigate the factors influencing modern contraceptive use among women of reproductive age in Tanzania.

\section{Materials and Methods}

\subsection{Setting and Data Source}

Tanzania is among the East African countries, with a population estimated to be 45,000,000 with high fertility rate 5.4. This study used Tanzania Demographic Health Survey (TDHS) to investigate predictors of modern 
contraceptive use. The TDHS is national representative household sample surveys that assess the population socio-demographic, maternal and child health, and various health indicators. The DHS is an important source of data to study health of the population due to its coverage (representativeness), data quality and comparability across the country. The coverage of the TDHS is population from Tanzania mainland and Zanzibar for both rural and urban populations.

The two stage probability sampling procedure was employed to select clusters and households. Based in the 2002 population and housing census, a total of 475 clusters were selected. DHS involves stratified cluster randomized samples of households. First stage sampling frame was stratified by urban and rural strata within each stratum. A random cluster of households were drawn from the list of all enumerated areas taken from the population census.

Household survey was carried out in all selected clusters between July and August 2009 and random selections of 10,300 households were selected from each of the clusters in all 26 regions of Tanzania. Out of 10,300 households 9623 households were successfully participated, within each sampled household a household questionnaire was administered and women eligible were identified and interviewed aged 15 - 49 years yielding a household response rate of 99\%. In the interviewed households 10,522 women were identified for individual interview. Of these, 10,139 women aged 15 - 49 years completed the interviews, yielding a response rate of $96 \%$. The reason for non-response was failure to trace the respondent at their home despite repeated visits. The household questionnaire was used to list all the usual members and visitors in the selected households. Details of sampling methods for the survey are available from [10] [11].

Our sample comprised of 6412 women who were currently married/ living with a partner, was used to determine modern contraceptive prevalence rate (CPR) and selected predictor variables (women empowerment, male-female age difference, advised from health care facility). In order to explore the relationship between intimacy partner violence (IPV) and contraceptive use, a subsample of 4471 female (Figure 1) who were interviewed about domestic violence module was analyzed.

\subsection{Study Design}

This was a cross-sectional study conducted using Tanzania Demographic Health Survey (TDHS) of 2010 data to assess the determinants of modern contraceptive use among women of reproductive age (15 - 49 years).

\subsection{Data Collection}

To ensure comparability across parts of the country and times, the DHS employs intensive training of interviews, use standardized tools and techniques and pretesting of data collection tools/instruments. The DHS question-

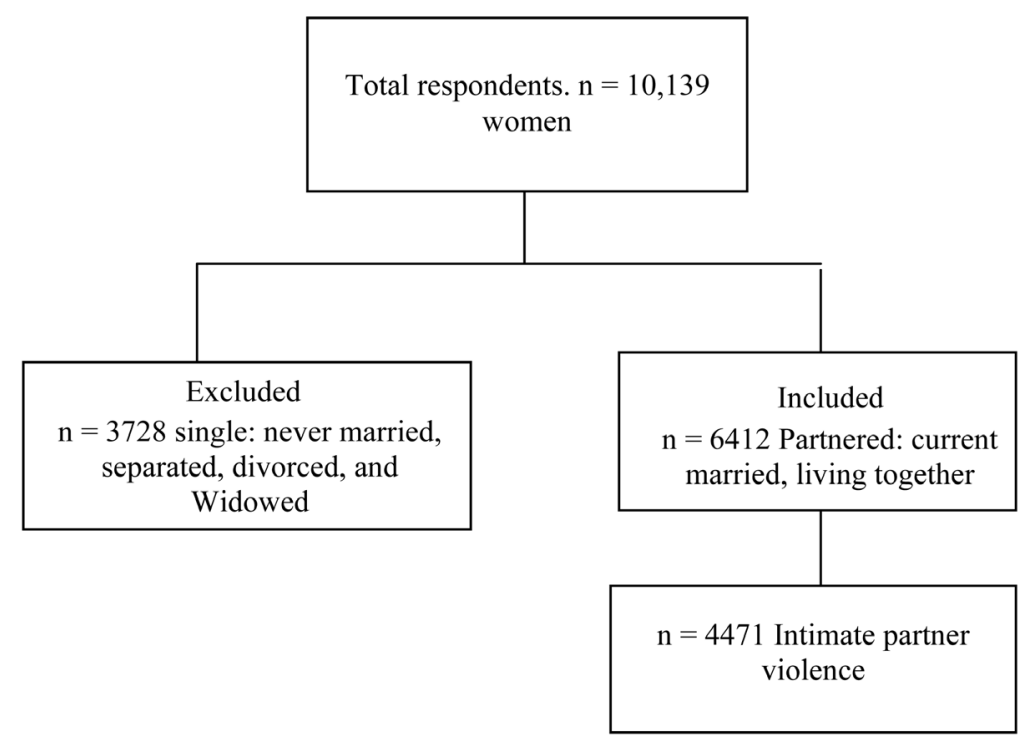

Figure 1. Flow chart for selection of participants. 
naire is standardized across the worldwide. However, the questions can be modified to meet local needs of the specific country and all stakeholders are involved for validation of the tool before the implementation of data collection. The DHS also use standardized variables across the survey to enhance the data quality and comparability.

Data collection was performed by face to face interview using three sets of questionnaires (the household questionnaire, the Women's Questionnaire, and the Men's Questionnaire). The content of these questionnaires were based on a validated model questionnaires developed by the MEASURE DHS to capture relevant issues in population and health in Tanzania [12]. Information on use of family planning were collected from 10,139 female using the women's questionnaire to obtain information on background characteristics of female and their partners, women reproductive history, use of antenatal (ANC), child mortality, number of previous pregnancy, postnatal care, childbirth and perinatal death, fertility preference and contraceptive use, knowledge on family planning methods type of method used, source of the contraception methods, maternal and child nutrition, infant feeding practices, gender-based violence and female genital mutilation. Information on knowledge, attitudes, and behaviour related to HIV/AIDS and other sexually transmitted infections (STIs) were also collected. Therefore, the DHS data allows estimation of reproductive and child health indictors for each region in the country.

\subsection{Statistical Analyses}

Data analysis was performed using Stata version 11.0. Since these were survey data, we applied weights to all descriptive statistics using v005 for individual record (first model) and d005 when describing domestic violence variable (second model). Descriptive statistics were used to summarize mean and standard deviation for continuous variables and proportion, for categorical variables. Unadjusted and adjusted odds ratios (ORs) with 95\% confidence intervals (CIs) were estimated in a logistic regression models to determine the association between modern contraceptive use and number of explanatory variables. A P-value of less than $<0.05$ was considered statistically significant. The selection criterion for the explanatory for inclusion in the final logistic regression model was based on its significant association with modern contraceptive use in a univariate analysis. Confounding variable was entered in a model one after a time to determine its contribution on the outcome of interest (modern contraceptive use). The confounding was considered to be present when the adjusted odd ratios change from unadjusted estimate by $10 \%$ or more.

\subsection{Ethical Clearance}

Permission to use the TDHS 2010 data granted from the DHS MEASURE, in which they have got permission from National Bureau of Statistics to collect data. The study was approved by KCMUCo Research and Ethical Review committee.

\section{Results}

\subsection{Socio-Demographic and Economic Characteristics of the Participants}

Our results is based on a sample of 6412 women of reproductive age (15 - 49 years), whose their characteristics are summarized in Table 1. The mean age (SD) for women and their partners was 31.8 (8.5) vs 39.3 (11.2) years respectively. Majority 4763 (75.3\%) of the respondents were from rural area. More than two-third 4395 (68.6\%) of the women and majority 4653 (73.0\%) of their partners had primary education. Most 5631 (88.7\%) of the female participants were employed. There was almost equal representation among participants who were poor and those who were rich 2509 (39.1\%) vs. 2570 (40.1\%), respectively.

\subsection{Factors Associated with Modern Contraceptive}

Findings from Multivariate Logistic Analysis Have Been Presented in Table 2 and Table 3

The use of modern contraceptive after adjusted with other variables, was almost two times higher (OR $=1.5$; $95 \%$ CI: 0.88 - 2.66) among partners with same age and 1.6 fold (95\% CI: 1.10 - 2.33) for age difference of less or equal to 9 years compared to women who are older than their partners. Compared with women with partners who had no education, women with male partners who had primary or secondary had seventy five percentage $(\mathrm{OR}=1.75 ; 95 \% \mathrm{CI}: 1.38-2.22)$ and two times $(\mathrm{OR}=2.07 ; 95 \% \mathrm{CI}: 1.53-2.81)$ likely to use contraceptive. 
Table 1. Socio-demographic characteristics of women of reproductive age $(n=6412)$.

\begin{tabular}{|c|c|c|}
\hline Characteristics & $\mathrm{N}$ & $\%$ \\
\hline \multicolumn{3}{|l|}{ Age of women } \\
\hline $15-19$ & 399.3 & 6.2 \\
\hline $20-24$ & 1210.3 & 18.9 \\
\hline $25-29$ & 1338.0 & 20.9 \\
\hline $30-34$ & 1137.3 & 17.7 \\
\hline $35-39$ & 1036.1 & 16.2 \\
\hline $40-44$ & 741.0 & 11.6 \\
\hline $45-49$ & 549.6 & 8.6 \\
\hline \multicolumn{3}{|l|}{ Age of partner } \\
\hline $17-19$ & 46 & 1.0 \\
\hline $20-24$ & 375 & 5.9 \\
\hline $25-29$ & 943 & 14.7 \\
\hline $30-34$ & 1162 & 18.1 \\
\hline $35-39$ & 1109 & 17.3 \\
\hline $40-44$ & 915 & 14.3 \\
\hline $45-49$ & 752 & 11.7 \\
\hline $50+$ & 1073 & 16.7 \\
\hline Missing & 37 & 0.6 \\
\hline \multicolumn{3}{|l|}{ Marital status } \\
\hline Cohabiting & 503 & 7.8 \\
\hline Married & 5909 & 92.2 \\
\hline \multicolumn{3}{|l|}{ Women education } \\
\hline No education & 1525 & 23.8 \\
\hline Primary & 4395 & 68.6 \\
\hline Secondary & 469 & 7.3 \\
\hline Higher & 23 & 0.4 \\
\hline \multicolumn{3}{|l|}{ Partner education } \\
\hline No education & 1011 & 15.8 \\
\hline Primary & 4653 & 72.6 \\
\hline Secondary & 654 & 10.2 \\
\hline Higher & 94 & 1.5 \\
\hline \multicolumn{3}{|c|}{ Occupation of women } \\
\hline No & 731 & 11.4 \\
\hline Yes & 5681 & 88.6 \\
\hline \multicolumn{3}{|l|}{ Partner occupation } \\
\hline No & 4692 & 73.2 \\
\hline Yes & 1720 & 26.8 \\
\hline \multicolumn{3}{|l|}{ Residence } \\
\hline Urban & 1585 & 24.7 \\
\hline Rural & 4827 & 75.3 \\
\hline \multicolumn{3}{|l|}{ Wealth } \\
\hline Poorer & 2509 & 39.1 \\
\hline Middle & 1333 & 20.8 \\
\hline Rich & 2570 & 40.1 \\
\hline
\end{tabular}


Table 2. Logistic regression model of association between baseline characteristics and current contraceptive use.

\begin{tabular}{|c|c|c|c|c|c|c|c|c|}
\hline \multirow{2}{*}{$\begin{array}{c}\text { Variables } \\
\text { Male-female age } \\
\text { difference (years) }\end{array}$} & \multicolumn{2}{|c|}{$\begin{array}{l}\text { Contraceptive } \\
\text { use }\end{array}$} & \multirow[t]{2}{*}{ Crude OR } & \multirow[t]{2}{*}{$95 \% \mathrm{CI}$} & \multirow[t]{2}{*}{$P$ value } & \multirow[t]{2}{*}{ Adjusted OR } & \multirow[t]{2}{*}{$95 \%$ CI } & \multirow[t]{2}{*}{$P$ value } \\
\hline & $\begin{array}{l}\text { Total } \\
\text { (n) }\end{array}$ & $\begin{array}{l}\text { Yes } \\
(\%)\end{array}$ & & & & & & \\
\hline Women older & 50 & 21.1 & 1.0 (referent) & & & 1.0 & & \\
\hline Same age & 55 & 28.2 & 1.50 & $0.91-2.38$ & 0.117 & 1.50 & $0.88-2.66$ & 0.135 \\
\hline Man older $\leq 9$ & 1236 & 29.1 & $1.54^{*}$ & $1.09-2.16$ & 0.013 & $1.60^{* *}$ & $1.10-2.33$ & 0.014 \\
\hline Man older $>9$ & 403 & 23.8 & 1.17 & $0.82-1.66$ & 0.386 & 1.21 & $0.82-1.80$ & 0.332 \\
\hline \multicolumn{9}{|l|}{ Partner education } \\
\hline No education & 154 & 15.3 & 1.0 (referent) & & & 1.0 & & \\
\hline Primary & 1325 & 28.5 & $2.21^{* * *}$ & $1.78-2.74$ & $<0.001$ & $1.75^{* * *}$ & $1.38-2.22$ & $<0.001$ \\
\hline Secondary & 245 & 37.5 & $3.32^{* * *}$ & $2.49-4.43$ & $<0.001$ & $2.07^{* * *}$ & $1.53-2.81$ & $<0.001$ \\
\hline College & 30 & 32.4 & $2.65^{* * *}$ & $1.54-4.57$ & $<0.001$ & 1.28 & $0.70-2.37$ & 0.424 \\
\hline \multicolumn{9}{|l|}{$\begin{array}{l}\text { Husband aware wife using } \\
\text { contraceptive }\end{array}$} \\
\hline No & 220 & 83.8 & 1.0 (referent) & & & & & \\
\hline Yes & 1373 & 87.5 & 1.36 & $0.85-2.18$ & 0.201 & - & - & - \\
\hline \multicolumn{9}{|l|}{$\begin{array}{l}\text { Decision maker for } \\
\text { contraceptive use }\end{array}$} \\
\hline Women & 367 & 85.1 & 1.0 (referent) & & & & & \\
\hline Partner & 184 & 77.8 & 0.61 & $0.34-1.12$ & 0.109 & 0.65 & $0.33-1.26$ & 0.200 \\
\hline $\begin{array}{l}\text { Joint decision } \\
\text { Child desire }\end{array}$ & 1204 & 78.5 & $0.64^{*}$ & $0.44-0.93$ & 0.020 & 0.52 & $0.32-0.83$ & 0.006 \\
\hline Both want same & 787 & 30.8 & 1.0 (referent) & & & 1.0 & & \\
\hline Husband wants more & 25 & 20.5 & $0.58^{* * *}$ & $0.48-0.70$ & $<0.001$ & $0.69^{* *}$ & $0.55-0.85$ & $<0.001$ \\
\hline Husband wants fewer & 91 & 27.9 & 0.87 & $0.61-1.25$ & 0.451 & 0.82 & $0.55-1.21$ & 0.314 \\
\hline I don't know & 324 & 18.9 & $0.52^{* * *}$ & $0.43-0.64$ & $<0.001$ & $0.61^{* * *}$ & $0.49-0.76$ & $<0.001$ \\
\hline
\end{tabular}

Advise on modern contraceptive at health facility

\begin{tabular}{lcccccccc} 
No & 631 & 26.9 & 1.0 (referent) & \multicolumn{7}{c}{1.0} & & \\
Yes & 701 & 35.6 & $1.50^{* * *}$ & $1.27-1.77$ & $<0.001$ & $1.63^{* * *}$ & $1.37-1.95$ & $<0.001$
\end{tabular}

Wife beating attitude

$\begin{array}{lcccccccc}\text { No } & 94 & 20.7 & 1.0 \text { (referent) } & & & 1.0 & & \\ \text { Yes } & 1661 & 27.9 & 1.48^{* *} & 1.11-1.97 & 0.008 & 1.33 & 0.97-1.84 & 0.076\end{array}$

Women empowerment

\begin{tabular}{|c|c|c|c|c|c|c|c|c|}
\hline No & 1120 & 25.1 & 1.0 (referent) & & & 1.0 & & \\
\hline Yes & 635 & 32.7 & $1.45^{* * *}$ & $1.27-1.66$ & $<0.001$ & $1.34^{* * *}$ & $1.16-1.56$ & 0.001 \\
\hline \multicolumn{9}{|l|}{ Residence } \\
\hline Urban & 540 & 34.1 & 1.0 (referent) & & & 1.0 & & \\
\hline Rural & 1215 & 25.2 & $0.65^{* * *}$ & $0.53-0.80$ & $<0.001$ & 1.07 & $0.82-1.40$ & 0.626 \\
\hline \multicolumn{9}{|c|}{ Women age } \\
\hline \multicolumn{9}{|l|}{ Wealth } \\
\hline Poor & 518 & 20.6 & 1.0 (referent) & & & 1.0 & & \\
\hline Middle & 309 & 23.2 & 1.16 & $0.96-1.40$ & 0.133 & 1.09 & $0.89-1.34$ & 0.398 \\
\hline Rich & 929 & 36.1 & $2.18^{* * *}$ & $1.82-2.60$ & $<0.001$ & $1.83^{* * *}$ & $1.44-2.32$ & $<0.001$ \\
\hline
\end{tabular}

Adjusted for age difference, partner education, residence, wealth, child desire, at health facility told family planning women empowerment, wife beating. Significant at ${ }^{* * *} \mathrm{P}<0.001,{ }^{* * *} \mathrm{P}<0.01,{ }^{*} \mathrm{P}<0.05$. Wealth was measured using asset ownership. 
Table 3. Logistic regression model of intimate partner violence and currently using modern contraception.

\begin{tabular}{|c|c|c|c|c|c|c|c|}
\hline \multirow{2}{*}{ Variables } & \multicolumn{2}{|c|}{ Contraceptive use } & \multirow{2}{*}{ Crude OR } & \multirow{2}{*}{$95 \%$ CI } & \multirow{2}{*}{ Adjusted OR } & \multirow{2}{*}{$95 \%$ CI } & \multirow{2}{*}{ P-value } \\
\hline & Total (n) & Yes (\%) & & & & & \\
\hline \multicolumn{8}{|l|}{ Physical violence } \\
\hline No & 862 & 27.9 & 1 (referent) & & & & \\
\hline Yes & 385 & 27.8 & 0.99 & $0.82-1.20$ & 0.96 & $0.75-1.21$ & 0.711 \\
\hline \multicolumn{8}{|l|}{ Sexual violence } \\
\hline No & 1096 & 28.0 & 1 (referent) & & & & \\
\hline Yes & 151 & 27.5 & 0.98 & $0.76-1.25$ & 0.96 & $0.70-1.31$ & 0.786 \\
\hline \multicolumn{8}{|l|}{$\begin{array}{l}\text { Male controlling } \\
\text { behavior }\end{array}$} \\
\hline No & 264 & 23.7 & 1 (referent & & & & \\
\hline Yes & 983 & 29.3 & $1.34^{* *}$ & $1.08-1.66$ & $1.6^{* * *}$ & $1.21-2.04$ & 0.001 \\
\hline \multicolumn{8}{|l|}{ Women empowerment } \\
\hline No & 808 & 25.8 & 1 (referent) & & & & \\
\hline Yes & 439 & 32.8 & $1.41^{* * *}$ & $1.19-1.67$ & $1.35^{* * *}$ & $1.10-1.66$ & 0.004 \\
\hline \multicolumn{8}{|l|}{ Wife beating attitude } \\
\hline No & 72 & 22.9 & 1 (referent) & & & & \\
\hline Yes & 1,176 & 28.3 & 1.33 & $0.86-2.05$ & 0.98 & $0.64-1.50$ & 0.64 \\
\hline \multicolumn{8}{|l|}{$\begin{array}{l}\text { Decision maker for } \\
\text { contraceptive use }\end{array}$} \\
\hline Women & 263 & 83.7 & 1. (referent) & & & & \\
\hline Partner & 122 & 77.8 & 0.68 & $0.35-1.33$ & & & \\
\hline Joint decision & 863 & 79.5 & 0.76 & $0.48-1.19$ & & & \\
\hline \multicolumn{8}{|l|}{$\begin{array}{l}\text { Husband aware wife } \\
\text { using contraceptive }\end{array}$} \\
\hline No & 154 & 79.8 & 1 (referent) & & 1.0 & & \\
\hline Yes & 980 & 88.0 & $1.86^{*}$ & $1.05-3.29$ & 1.25 & $0.68-2.30$ & 0.47 \\
\hline \multicolumn{8}{|l|}{ Child desire } \\
\hline Both want same & 554 & 30.9 & 1 (referent) & & & & \\
\hline Husband wants more & 238 & 21.0 & $0.59^{* * *}$ & $0.48-0.74$ & 0.64 & $0.34-1.19$ & 0.157 \\
\hline Husband wants fewer & 64 & 27.2 & 0.83 & $0.55-1.27$ & 0.54 & $0.19-1.56$ & 0.254 \\
\hline Don’t know & 228 & 20.0 & $0.56^{* * *}$ & $0.43-0.72$ & 0.96 & $0.52-1.76$ & 0.892 \\
\hline
\end{tabular}

Adjusted for physical violence, sexual violence, controlling behavior of male partner, wife beating attitude, residence, child desire, at health facility told family planning, women empowerment. Significant at ${ }^{* * *} \mathrm{P}<0.001,{ }^{* *} \mathrm{P}<0.01,{ }^{*} \mathrm{P}<0.05$.

Women whose their husband/partners willing to have another child and those who were not sure (I don't know) were ( $30 \%$ vs. $45 \%$ respectively) less likely to use contraceptive. Women who were empowered had high odds of using contraceptive (OR $=1.3$; 95\% CI: 1.16 - 1.56). Women who got information on contraceptive use at health facility had $40 \%(\mathrm{OR}=1.6,95 \%$ CI: $1.4-2.0)$ more likely to report using contraceptive as compared to their counterparts (Table 2). In addition, wife beating justified attitude was significantly in association with contraceptive use in the crude analysis but the association disappeared after controlling for potential confounders. There were no association between intimate partner violence (physical and sexual violence) and modern contraceptive use for domestic violence module $(\mathrm{P}>0.05)$ as shown in Table 3.

\section{Discussion}

In this study we assessed the determinants of modern contraceptive use among women of reproductive age. We 
found women empowerment, male-female age difference of less or equal to nine, and advised at health care facilities on family planning were predictors of modern contraceptive use.

\section{Comparison to Other Studies}

This study shows that woman having no age gap and age difference of less than or equal to 9 years of partners has higher odds of using modern contraceptive use compared with women who are older than their partners. There was an increase in FP use with as male age increases, women are less likely to use modern contraceptive. Age gap among couples could act as a power on decision making, as age gap increases women are likely to receive order from their husbands. This study is in consistent with [6] [13]-[15]. The plausible explanation could be both studies used DHS data that uses standardized questionnaires, however, the study was conducted in similar low income countries. Male-age difference has an impact on modern contraceptive use in which women are placed in high risk during their lifetime especially maternal life risk time.

This study shows that child desire was negatively associated with use of modern contraceptive. This finding is similar to previous studies [2] [7] [16]-[18]. In the present study when husbands want more children, women were less likely to use contraceptives compared with when couples wants the same number of children. One possible explanation for this could be attributed to culture that allows men or families to have many children. In African countries the notion of children being an asset for future security has negative effect on utilization of contraceptive use as a consequence lead to poor interpregnancy interval and adverse pregnancy outcomes. If husband desire to have more children may lead to decreased contraceptive use, education and messages on family planning use is still needed to promote awareness in the community.

A finding from this study suggests that women who are empowered have greater odds of using contraceptive. These findings are similar with previous studies [10] [11] [19]-[21]. Empowerment gives freedom of choice, thus also can enable women to make better choice of modern contraceptive. In the other hand, women have an opportunity to discuss with their partners on the use of modern contraceptive. This has an impact not only to contraceptive use but also to reproductive health that in turn has good perinatal and maternal outcome thus reduce neonatal and maternal mortality rate.

In the present study, women who experienced physical violence had 14 percent decreased odds of contraceptive usage, but this association did not reach statistical significant. Low use of modern contraceptive could be a defensive mechanism to avoid conflicts and facilitate men's interest and culture during their future life time thus in turn leads to poor perinatal and maternal outcome. Previous author [18] has also reported that women who experience physical violence are less likely to use modern contraceptive. The lower usage of modern contraceptive in both studies could be explained by social cultural factors as reported. Our finding is contrary in a study done by Dalal and his colleagues in Bangaladesh [8], the woman who is found that experienced physical intimate partner violence used more contraceptives compared with those who did not experience such problem. The differences in our study and that of other authors explained the difference in physical violence that exists among regions which in turn reflect the extent of contraceptive use among regions.

This study shows that women who experienced sexual violence were less likely to use contraceptive though it was not statistically significant, probably women are reluctant to use contraceptive to satisfy men interest of desire for more children thus preventing divorce and future violence. Contraceptive use could be the source of conflict among couples, to escape from such harassment women are likely to withdraw from using contraceptive use to allow men's interest to prevail within the family. Similar in a study done by Dalal [8] and his colleagues found that sexual violence was not an important predictor for modern contraceptive use, contrary to a study done in Jordan by Montes, O’Hara and their colleagues [18] [22] found the odds of currently using contraception were greater for women who reported experiencing sexual violence compared those who did not. IPV could be associated with use of modern contraceptive among married/cohabiting women as means of protection for future problems especially unwanted pregnancy in case of sexual violence. Thus the public could face increased intimate partner violence in a community that have negative attitude towards modern contraceptive especially when men wants more children, however in another side IPV might be a source of reduced contraceptive use leading to unwanted pregnancy as well as poor perinatal and maternal outcome among women this in turn could lead to high neonatal and maternal mortality rate.

The predictors of modern contraceptive use in our study correspond with other studies in low income countries. Women empowerment, male-female age difference, child desire were important predictors for use of mod- 
ern contraceptives. However, prevalence of modern contraceptive use is still low. This highlights the need to promote contraceptive use, thus in turn contribute toward the reduction of neonatal and maternal mortality rate. Further studies are recommended to explore the association of controlling behavior of male partners, physical violence, sexual violence, wife beating, service provision and contraceptive use.

Our study has strength and limitations; one of the strength of this study is the large sample size which could be a representativeness of other women of reproductive age group in the general population, and thus making our results generalizable. The DHS data were collected using a standardized questionnaire which has been validated; this enables collection of most of information relevant for this study and hence minimizes information bias. However, some information were not collected in TDHS such as religion which is a known factor associated with contraceptive use thus limited to assess this factor. In addition, in subgroup analysis such as domestic violence in relation with contraceptive use, it was difficult to assess this association due to small number of subjects in each category resulting to low power.

Another limitation of using secondary source data is subject to missing of important information (Variables) and recall bias.

\section{Conclusions}

The predictors of modern contraceptive use in our study correspond with other studies in low income countries. Women empowerment, male-female age difference, and child desire were important predictors for use of modern contraceptives. However, prevalence of modern contraceptive use is still low. This highlights the need to promote contraceptive use, and thus in turn contribute toward the reduction of neonatal and maternal mortality rate. Further studies are recommended to explore the association of controlling behavior of male partners, physical violence, sexual violence, wife beating, service provision and contraceptive use.

Promoting modern contraceptive use will result to compliance to appropriate inter-pregnancy interval, and thus reduce adverse maternal and perinatal outcomes. It will lead to control of the current country population growth.

\section{Acknowledgements}

We thanks for Kilimanjaro Christian Medical University College and THRIVE for their financial support. We also extend thanks to DHS Measure, for allowing us to use TDHS 2010 dataset for this study.

\section{Competing Interests}

The author declared that they have no competing interests.

\section{References}

[1] WHO (2011) Unsafe Abortion, Global and Regional Estimates of Incidence of Unsafe Abortion and Associated Mortality in 2008. www.who.int/reproductivehealth/publications/unsafe_abortion/.../en/

[2] Singh, S., Darroch, J., Ashford, L. and Vlassoff, M. (2009) Adding It up: The Costs and Benefits of Investing in Family Planning and Maternal and Newborn Health. Guttmacher Institute, New York.

[3] Ezeh, A.C., Bongaarts, J. and Mberu, B. (2012) Global Population Trends and Policy Options. Lancet, 380, $142-148$. http://www.ncbi.nlm.nih.gov/pubmed/22784532 http://dx.doi.org/10.1016/S0140-6736(12)60696-5

[4] Alkema, L., Kantorova, V., Menozzi, C. and Biddlecom, A. (2013) National, Regional, and Global Rates and Trends in Contraceptive Prevalence and Unmet Need for Family Planning between 1990 and 2015: A Systematic and Comprehensive Analysis. Lancet, 381, 1642-1652. http://dx.doi.org/10.1016/S0140-6736(12)62204-1

[5] United Republic of Tanzania, National Bureau of Statistics (2011) Tanzania Demographic and Health Survey (2010). Edited by Reproductive and Child Health Section, Dar es Salaam.

[6] Aryeetey, R., Kotoh, A.M. and Hindin, M.J. (2010) Knowledge, Perceptions and Ever Use of Modern Contraception among Women in the Ga East District, Ghana. African Journal of Reproductive Health, 14, 29.

[7] Samandari, G., Speizer, I.S. and O’Connell, K. (2010) The Role of Social Support and Parity on Contraceptive Use in Cambodia. International Perspectives on Sexual and Reproductive Health, 36, 122-131.

http://dx.doi.org/10.1363/3612210 
[8] Dalal, K., Andrews, J. and Dawad, S. (2011) Contraception Use and Associations with Intimate Partner Violence among Women in Bangladesh. Journal of Biosocial Science, 44, 83-94. http://dx.doi.org/10.1017/S0021932011000307

[9] Mohammed, A., Woldeyohannes, D., Feleke, A. and Megabiaw, B. (2014) Determinants of Modern Contraceptive Utilization among Married Women of Reproductive Age Group in North Shoa Zone, Amhara Region, Ethiopia. Journal of Reproductive Health, 11, 13. http://dx.doi.org/10.1186/1742-4755-11-13

[10] Tadesse, M., Teklie, H., Yazew, G. and Gebreselassie, F. (2013) Women’s Empowerment as a Determinant of Contraceptive Use in Ethiopia: Further Analysis of the 2011 Ethiopia Demographic and Health Survey and Health Survey. DHS Further Analysis Reports No. 82. ICF International, Calverton.

[11] The United Republic of Tanzania, National Bureau of Statistics (2002) Population and Housing Census; General Report. Edited by National Bureau of Statistics, Vol. II, Dar es Salaam.

[12] Hameed, W., Azmat, K.S., Ali, M., Sheikh, I.M., Abbas, G., Temmerman, M. and Avan, I.B. (2014) Women’s Empowerment and Contraceptive Use: The Role of Independent versus Couples’ Decision-Making, from a Lower Middle Income Country Perspective. PLoS ONE, 9, e104633.

[13] Barbieri, M. and Hertrich, V. (2005) Age Difference between Spouses and Contraceptive Practice in Sub-Sahara Africa. JSTOR, 60, 5-6.

[14] Das, K.C., Gauta, V., Das, K. and Tripathy, P.K. (2011) Influence of Age Gap between Couples on Contraception and Fertility. The Journal of Family Welfare, 57, 30-38.

[15] Ibisomi, L. (2014) Is Age Difference between Partners Associated with Contraceptive Use among Married Couples in Nigeria? International Perspectives on Sexual and Reproductive Health, 40, 39-45. http://dx.doi.org/10.1363/4003914

[16] Mosha, I., Ruben, R. and Kakoko, D. (2013) Family Planning Decisions, Perceptions and Gender Dynamics among Couples in Mwanza Tanzania: A Qualitative Study. BMC Public Health, 13, 523. http://dx.doi.org/10.1186/1471-2458-13-523

[17] Irani, L., Speizer, I.S. and Fotso, J.C. (2014) Relationship Characteristics and Contraceptive Use among Couples in Urban Kenya. International Perspectives on Sexual and Reproductive Health, 40, 11-20. http://dx.doi.org/10.1363/4001114

[18] O’Hara, K., Tsai, L.C., Carlson, C.E. and Haidar, Y.M. (2013) Experiences of Intimate-Partner Violence and Contraception Use among Ever-Married Women in Jordan. Eastern Mediterranean Health Journal, 19, 876-882.

[19] The United Republic of Tanzania, Ministry of Health and Social Welfare (2010) National Family Planning Costed Implementation Program 2010-2015. Ministry of Health and Social Welfare, Dar es Salaam.

[20] Osemwenkha, O.S. (2004) Gender Issues in Contraceptive Use among Educated Women in Edo State, Nigeria. African Health Sciences, 4, 40-49.

[21] Kurimoto, N. and Do, M. (2012) Women’s Empowerment and Choice of Contraceptive Methods in Selected African Countries. International Perspectives on Sexual and Reproductive Health, 38, 23-33. http://dx.doi.org/10.1363/3802312

[22] Montes, R.B. and Cruz, E.L. (2014) Bayesian Logistic Regression Analysis of the Association of Intimate Partner Violence and Modern Contraceptive Use in the Philippines. Asian Journal of Social Sciences and Humanities, 3, $142-$ 150. 